\title{
Apresentação: literatura e ditadura
}

\author{
Presentation: Literature and Dictatorship \\ Presentación: literatura y dictadura \\ Rita Olivieri-Godet ${ }^{*}$ \\ Mireille Garcia ${ }^{* *}$
}

Um passado que teima em não passar. Esta asserção tornou-se um lugar-comum, no atual contexto brasileiro, no qual ecoam os gritos que pedem a volta à ditadura, reativando os fantasmas do totalitarismo. "No Brasil atual", afirma Marcia Tiburi (2016, p. 152), "não devemos acobertar o fato de um crescimento de tendências fascistas, de ódio ao outro, a negros, índios, homossexuais". Sabe-se que, contrariamente a outros países da América Latina, a exemplo da Argentina, o Estado brasileiro recusou-se a fazer o trabalho de desconstrução do simbolismo autoritário dos atores da ditadura. Por conseguinte, seus representantes não se empenharam em investir na criação de lugares de memória, entendidos como arquivos da memória traumática que expõem a barbárie e bloqueiam o trabalho do esquecimento (Nora, 1997, p. 38). Em vez disso, reprimiu a memória do trauma e promulgou a Lei da Anistia "ampla e irrestrita", que construiu o amálgama entre torturadores e vítimas, imputando a ambos a mesma culpabilidade. $\mathrm{Na}$ contramão dessa tendência, uma parcela significativa da produção artística e literária brasileira vem se dedicando a reacender a memória de um tempo de sombras de onde emergem os espectros da violência para nos aterrorizar no presente. O campo literário participa desse trabalho de questionamento e revisão histórica, denunciando a herança da violência no quotidiano, contribuindo, dessa maneira, para transformar o cenário simbólico.

A crítica e a criação literárias têm refletido sobre a violência das relações autoritárias como uma das marcas consubstanciais da sociedade brasileira. A representação da Ditadura Militar e do seu legado autoritário originou textos escritos no calor da hora, relatos testemunhais e memorialísticos de vítimas da repressão ou, mais recentemente, romances de autores mais jovens, nascidos em torno de 1964, que, sem ter sido vítimas diretas da violência da Ditadura Militar, refletem e transfiguram essa experiência, como observa Eurídice Figueiredo (2017) no mapeamento que realiza dessa produção. A persistência da memória traumática da Ditadura Militar na produção literária brasileira é um sintoma do interesse renovado pela temática, ao longo de mais de meio século, que se poderia justificar pelas consequências da barbárie na contemporaneidade brasileira alimentada pela onipresença de um "inimigo que não parou de vencer" (Benjamin, 2006, p. 11). O trabalho de rememoração efetuado pela literatura enfrenta o apagamento dos rastros do passado recente no imaginário social, fazendo emergir as "memórias do esquecimento" - alusão ao título do livro do jornalista e professor de direito da Universidade de Brasília Flávio Tavares (1999), preso e torturado durante a Ditadura Militar -, devolvendo ao presente os gritos silenciados no passado.

Os estudos críticos reunidos neste número da revista Estudos de Literatura Brasileira Contemporânea cobrem desde textos editados nas duas últimas décadas do século $\mathrm{XX}$, relacionados com a memória de experiências vividas, até os publicados no século XXI, majoritariamente representados neste dossiê por escritores de uma segunda geração que exploram a memória familiar, interconectando a subjetividade do sujeito ao político. Os artigos examinam os procedimentos estéticos que desvelam, entre outras questões, a persistência das marcas do autoritarismo nas relações sociais e políticas, a representação brutal da violência, a hipertrofia do poder policial, a dimensão íntima e subjetiva da história, a experiência do exílio, as tensões entre

\footnotetext{
*Université Rennes 2, Rennes, Bretanha, França. Dorcid.org/0000-0003-0635-5673 E-mail : ritagodet20@gmail.com

${ }^{* *}$ Université Rennes 2, Bretanha, França. (Dorcid.org/0000-0001-8203-0294 E-mail: mireillebrfr@hotmail.com
} 
memória, esquecimento e ocultamento do trauma. No contexto atual da sociedade brasileira, marcado pelo eco da ideologia totalitária a qual considera os seres humanos como instrumentos para realização de um projeto político, como lembra Todorov em Face à l'extrême (1994), as estratégias utilizadas pela produção literária contemporânea intervêm na rede dos discursos sociais, problematizando as relações com o referencial histórico, interrogando as narrativas anteriores ao tempo em que estabelecem as pontes com o presente. As análises que integram este dossiê examinam os procedimentos estético-discursivos adotados pelos textos literários, explorando suas relações com o social e o político e interpelando as configurações das dinâmicas da memória. Os textos examinados e a perspectiva de abordagem dos estudos críticos que lhes são consagrados manifestam a consciência de que, como observa Márcio Seligmann-Silva (2000, p. 102), "a construção da memória do passado, e [...] a construção do conhecimento histórico dependem de interesses ideológicos e de lutas políticas que pertencem ao presente".

A função da literatura como espaço periférico de liberdade, que permite dar voz e corpo às vítimas, é destacada no artigo de abertura do presente dossiê, "O corpo expropriado: Bernardo Kucinski - diário de uma perda", de Ettore Finazzi-Agrò. O crítico e professor da Universidade de Roma "La Sapienza" discute o papel do testemunho literário, apontando, igualmente, para os limites do processo de recuperação da memória pessoal e coletiva, tomando como corpus as obras K.: relato de uma busca e Os visitantes, de Bernardo Kucinski. Em sua análise da representação da situação traumática que os textos abordam, a que diz respeito aos desaparecidos da Ditadura Militar brasileira e ao drama dos sobreviventes a um corpo expropriado, FinazziAgrò destaca o entrelaçamento dessas narrativas. Segundo o autor, esses textos expõem, por um lado, a impossibilidade de restituir por completo uma verdade apagada pela extrema opressão política, enquanto, por outro lado, dão ênfase à dificuldade de fazê-la emergir num contexto histórico atual de um novo regime autoritário onde impera a pós-verdade - uma verdade que simplifica e distorce, tendenciosamente, os acontecimentos reais.

O segundo artigo nos convida a prolongar a reflexão sobre "o corpo expropriado" ou, na expressão contundente da narradora do romance de Marcia Tiburi (2018, p. 94), a levar em consideração "o cadáver abandonado no necrotério da história": os desaparecidos, vítimas do terror da Ditadura Militar. Igualmente dedicado à reelaboração da memória dos crimes ditatoriais, o artigo de Marianna Scaramucci, "Monumentos precários: luto (im)possível e lápides de papel em K.: relato de uma busca", estabelece conexões entre literatura, artes plásticas e política, propondo uma perspectiva de abordagem que aproxima "a precariedade do saber", próprio do testemunho literário, da estética do antimonumento. A autora menciona, inicialmente, alguns "exercícios de monumentalização à contrapelo" (instalações, memoriais, cemitérios) que evocam a memória do terror ditatorial para, num segundo momento, dedicar-se à análise da construção da memória familiar e coletiva do trauma na narrativa de Kucinski, identificando a tensão entre lembrança e esquecimento como elemento que os aproxima.

Os dois estudos seguintes ocupam-se de uma mesma obra, a densa narrativa de Noite dentro da noite, de autoria de Joca Reiners Terron. O artigo de Rita Olivieri-Godet, "Estilhaços da memória no pântano da história: Noite dentro da noite de J. R. Terron", destaca a perspectiva niilista de um romance que busca captar a barbárie de uma "era dos extremos", ancorado na memória da ditadura de 1964, mas evocando, igualmente, o período que lhe antecede e que lhe é posterior, através do filtro de uma visão apocalíptica e profética. A autora aciona o conceito de pósmemória, de Marianne Hirsch (2013), para examinar os limites da representação de uma herança traumática, compartilhada de forma indireta por mediações diversas. Olivieri-Godet destaca as estratégias discursivas de uma escrita lacunar e angustiante, que dialoga intensamente com a tradição literária e com as diversas linguagens artísticas e midiáticas, elaborando imagens alegóricas da permanência da ancestralidade maldita - os espectros do passado - no presente.

Por sua vez, Cristiane Checchia, no artigo intitulado "Fronteiras e esquecimento: Noite dentro da noite de Joca Reiners Terron", fundamenta sua abordagem no conceito de memórias em trânsito (Erll, 2011; Huyssen, 2014), relacionadas com experiências de deslocamentos de diversas ordens: temporais, espaciais, territoriais, linguísticos. Por esse viés crítico, a autora ressalta o trânsito da memória para além dos diversos tipos de barreiras, apontando os 
deslocamentos temporais que se impõem tanto ao escritor, que, pertencendo a uma nova geração, herda a memória traumática da ditadura e flerta com o gênero da autoficção, quanto ao protagonista, o menino amnésico que introduz a perspectiva infantil que permeia a narrativa. Entre os múltiplos deslocamentos espaciais observados, Checchia destaca o fluxo entre cidades, o exílio e a construção da paisagem da fronteira do Pantanal, entre o Brasil e o Paraguai, remetendo aos conflitos memoriais, às experiências das ditaduras do Cone Sul, assim como à presença das personagens indígenas de diferentes etnias.

O trabalho de memória que transpõe as fronteiras nacionais das ditaduras sul-americanas prossegue, alimentando o diálogo entre literatura e memória, com a contribuição de Eurídice Figueiredo, "A resistência de Julián Fuks: uma narrativa de filiação". Do mesmo modo que Joca Reiners Terron, Julián Fuks é descendente de imigrantes e faz parte da segunda geração de escritores, aquela que herda o trauma familiar da Ditadura Militar. A autora lembra que Fuks é um dos escritores "filhos do exílio", que reconstrói ficcionalmente a experiência das migrações dos ancestrais, cuja família exilou-se em São Paulo, durante a Ditadura Militar na Argentina. A leitura, inspirada no conceito de narrativa de filiação de Dominique Viart (2008), destaca o deslocamento da investigação da interioridade em favor da anterioridade, ancorada na prospecção genealógica e numa escrita fragmentada e lacunar, imbricando as memórias das experiências individuais, familiares e geracionais. $\mathrm{O}$ estudo aponta para o hibridismo genérico de um texto que dialoga tanto com a ficção quanto com a autobiografia.

Dando continuidade às considerações sobre a reapropriação da memória familiar em obras de artistas brasileiros, pertencentes à geração de filhos dos exilados políticos, Ilana Heineberg adota uma perspectiva comparada, apoiando-se num corpus relativamente amplo, para discutir a questão que relaciona exílio e memória. No artigo "Exílio da ditadura na ficção brasileira da geração pós-memorial: a perspectiva e a estética dos filhos", a autora promove o diálogo entre as narrativas A chave de casa, de Tatiana Salem Levy; Mar azul, de Paloma Vidal; A resistência, de Julián Fuks; Rio-Paris-Rio, de Luciana Hidalgo; e o filme Deslembro, de Flávia Castro. O trabalho preocupa-se em precisar as circunstâncias da origem e da evolução do conceito de pós-memória de Marianne Hirsch, lembrando que este "descreve a relação que a 'geração seguinte' mantém com o trauma cultural, coletivo e pessoal vivido por aqueles que a precederam" (Hirsch, 2014). A proposta de Heineberg busca "delinear o que seria uma estética pós-memorial brasileira".

Em seu artigo "Da ocultação à memória difratada: a escrita da resiliência em Palavras cruzadas, de Guiomar de Grammont", Leonor Lourenço de Abreu destaca o papel fundamental da produção literária brasileira atual, relacionada com os anos de chumbo, não apenas como forma de curar a amnésia oficial, mas igualmente por significar um "convite à ação através da criação artística partilhada". É pelo viés da resiliência, conceito que pressupõe o enfrentamento e a superação dos traumatismos históricos através de uma dinâmica de ressignificação de um acontecimento traumatizante, que Leonor Lourenço de Abreu lê a fabulação romanesca transgressora que Guiomar de Grammont constrói em torno da Guerrilha do Araguaia: um dos massacres perpretados contra os jovens que aderiram à luta armada para combater a Ditadura Militar brasileira, sobre o qual se abateu a lei do silêncio. A análise minuciosa das estratégias ficcionais e discursivas sustenta a tese segundo a qual a construção narrativa de Grammont indica uma postura ética embasada na ideologia da tolerância, que escapa à lógica dicotômica.

O espectro da Guerrilha do Araguaia reaparece em Azul-corvo, de Adriana Lisboa. Num estudo comparativo com o romance Não falei, de Beatriz Bracher, Karina Marques desenvolve considerações sobre os mecanismos de (des)responsabilização criados pelo governo militar durante os anos de ditadura no Brasil (1964-1985), no artigo intitulado "Mea culpa e autopunição: o colaboracionista em Não falei, de Beatriz Bracher, e o desertor em Azul-corvo, de Adriana Lisboa". Karina Marques vale-se das noções de "violência sistêmica" e "violência subjetiva", de Žižek (2012), para analisar as figuras do delator, no primeiro romance, e a do desertor, no segundo, dando destaque à "Lei da Anistia", que descriminaliza o aparelho estatal, contribuindo para a instauração de uma "prática social de transferência da responsabilidade pelos crimes cometidos pelo regime aos cidadãos comuns". Reconhece o valor testemunhal dos romances analisados, 
empenhados em transmitir às novas gerações a experiência vivida na clandestinidade, mas destaca, sobretudo, o veio psicológico no tratamento do peso do legado histórico.

O conjunto de três artigos que fecham essa coletânea é dedicado a narrativas publicadas nas duas últimas décadas do século XX, atravessadas pelo teor testemunhal.

O artigo assinado por Alessia Di Eugenio e Roberto Vecchi, "A dupla cicatriz: a ditadura brasileira e a vocalização feminina da memória traumática de Ana Maria Machado", associa as questões de memória às de gênero na leitura dos romances Tropical sol da liberdade e Canteiros de Saturno. Os romances desenvolvem uma reflexão sobre as políticas da memória e a possibilidade de restituir as vozes silenciadas no contexto do Brasil pós-ditatorial. Apesar do efetivo envolvimento das mulheres no combate à ditadura, as narrativas de Ana Maria Machado são textos pioneiros no que diz respeito às escritas de mulheres sobre o período da ditadura brasileira e pós-ditadura. Atentos à dimensão metaliterária de Tropical sol da liberdade, os autores salientam a especificidade de uma escrita que, para restituir a voz feminina no contexto dos anos de chumbo, distancia-se de uma representação verossimilhante e imediata de uma certa literatura testemunhal, para explorar, em ambas as narrativas, a tensão entre experiência, história e memória, buscando deslindar as especificidades da memória feminina.

A discussão sobre o teor testemunhal da narrativa retém igualmente a atenção de Jacob Brown, no artigo "A arte como refúgio: intertextualidade, espaço e (imagi)nação em 'Aqueles dois', de Caio Fernando Abreu", no qual o autor se empenha em identificar e examinar as diversas referências intertextuais à arte, à poesia, à música e ao cinema no referido conto.

O estudo de Pedro Penhavel, "Leitura de Retrato calado, de Luiz Roberto Salinas Fortes: aproximações benjaminianas", que encerra esta coletânea de artigos, está focado na análise de um dos textos paradigmáticos da literatura de testemunho. O relato autobiográfico do filósofo e professor da Universidade de São Paulo sobre a perseguição política, as sucessivas prisões e sessões de tortura a que foi submetido durante a década de 1970 cumpre a tarefa, como lembra Penhavel, fundamentado na perspectiva teórica benjaminiana, de "escovar a história a contrapelo", estabelecendo um contraponto à historiografia enquanto relato imposto pelos vencedores. Discute as "motivações políticas e subjetivas para a escrita", articulando-as com as ferramentas centrais da construção da narrativa na obra de Salinas. A importância fundamental do ato de rememoração é destacada pelo autor ao reproduzir a citação de Jeanne Marie Gagnebin, da qual nos apropriamos por considerarmos oportuna para encerrar a apresentação deste dossiê em torno da temática "Literatura e ditadura":

A rememoração também significa uma atenção precisa ao presente, em particular a estas estranhas ressurgências do passado no presente, pois não se trata somente de não se esquecer do passado, mas também de agir sobre o presente. A fidelidade ao passado, não sendo um fim em si, visa à transformação do presente (Gagnebin, 2006, p. 55).

\section{Referências}

BENJAMIN, Walter (1994). Sobre o conceito de história. BENJAMIN, Walter. In: Magia e técnica, arte e politica: ensaios sobre literatura e história da cultura. Tradução de Sergio Paulo Rouanet. 7. ed. São Paulo: Brasiliense. p. 222-232.

BENJAMIN, Walter (2006). Passagens. Tradução de Irene Aron e Cleonice P. B. Mourão. Belo Horizonte: UFMG; Imprensa Oficial de São Paulo.

ERLL, Astrid (2011). Traumatic pasts, literary afterlives, and transcultural memory: new directions of literary and media memory studies. Journal of Aesthetics \& Culture, Londres, v. 3, p. 1-5.

FIGUEIREDO, Eurídice (2017). A literatura como arquivo da ditadura brasileira. Rio de Janeiro: 7 Letras.

GAGNEBIN, Jeanne Marie (2006). Lembrar escrever esquecer. São Paulo: Editora 34.

HIRSCH, Marianne (1997). Family frames: photography, narrative and postmemory. Cambridge; London: Harvard University Press. 
HIRSCH, Marianne (2012). The generation of postmemory: writing and visual culture after the Holocaust. Cambridge; London: Harvard University Press.

HIRSCH, Marianne (2014). Connective histories in vulnerable times. PMLA, v. 129, n. 3, May, p. 330-348. Disponível em: https:// bit.ly/3e04geh. Acesso em: 20 mar. 2020.

HIRSH, Marianne (2013). Postmémoire/Postmemory. Entretien avec Marianne Hirsch. An interview with Marianne Hirsch. Art Absolument, Paris, n. esp., p. 6-11, abr. Disponível em: https://bit.ly/2RkAfvY. Acesso em: 20 mar. 2020.

HUYSSEN, Andreas (2014). Culturas do passado-presente: modernismos, artes visuais, políticas da memória. Rio de Janeiro: Contraponto; Museu de Arte do Rio.

NORA, Pierre (Dir.) (1997). Les lieux de mémoire. Paris: Gallimard.

SELIGMANN-SILVA, Márcio (2000). A história como trauma. In: SELIGMANN-SILVA, Márcio; NESTROVSKI, Arthur. (Org.). Catástrofe e representação. São Paulo: Escuta. p. 73-98.

TAVARES, Flávio (1999). Memórias do esquecimento. Porto Alegre: L\&PM.

TIBURI, Marcia (2016). Como conversar com um fascista. Rio de Janeiro: Record.

TIBURI, Marcia (2018). Sob os pés, meu corpo inteiro. Rio de Janeiro: Record.

TODOROV, Tzvetan (1994). Face à l'extrême. Paris: Seuil; Points.

VIART, Dominique, VERCIER, Bruno (2008). La littérature française au présent. Héritage, modernité, mutations. Avec la collaboration de Franck Evrard. Paris: Bordas.

ŽIŽEK, Slavoj (2012), Violence: la violence n'est pas un accident de nos systèmes, elle en est la cause. Paris: Au Diable Vauvert. 